\title{
A New Functional Scale and Ambulatory Functional Classification of Duchenne Muscular Dystrophy: Scale Development and Preliminary Analyses of Reliability and Validity
}

\author{
Jungyoon Kim, MD, PhD ${ }^{1,2}$, Il-Young Jung, $\mathrm{MD}^{1,3}$, Sang Jun Kim, MD, $\mathrm{PhD}^{1,4}$, Joong-Yulb Lee, MD, $\mathrm{PhD}^{5}$, \\ Sue Kyung Park, MD, PhD ${ }^{6,7,8}$, Hyung-Ik Shin, MD, PhD ${ }^{1}$, Moon Suk Bang, MD, PhD
}

\begin{abstract}
${ }^{1}$ Department of Rehabilitation Medicine, Seoul National University College of Medicine, Seoul; ${ }^{2}$ Ewha Brain Institute, Ewha Womans University, Seoul; ${ }^{3}$ Department of Physical Medicine and Rehabilitation, Chungnam National University Hospital, Daejeon; ${ }^{4}$ Department of Physical and Rehabilitation Medicine, Samsung Medical Center, Sungkyunkwan University School of Medicine, Seoul; ${ }^{5}$ Medical Research Collaborating Center, Seoul National University Hospital, Seoul National University College of Medicine, Seoul; ${ }^{6}$ Department of Preventive Medicine, Seoul National University College of Medicine, Seoul; ${ }^{7}$ Department of Biomedical Science, Graduate School of Seoul National University, Seoul; ${ }^{8}$ Cancer Research Institute, Seoul National University, Seoul, Korea
\end{abstract}

Objective To develop a simplified functional scale and classification system to evaluate the functional abilities of patients with Duchenne muscular dystrophy (DMD).

Methods A Comprehensive Functional Scale for DMD (CFSD) was developed using the modified Delphi method. The accompanying Ambulatory Functional Classification System for DMD (AFCSD) was developed based on previously published classification systems.

Results The CFSD consists of 21 items and 78 sub-items, assessing body structure and function, activities, and participation. Inter-rater intraclass correlation coefficient values were above 0.7 for 17 items. The overall limits of agreement between the two examiners ranged from -6.21 to 3.11 . The Spearman correlation coefficient between the total score on the AFCSD and the Vignos Functional Scale was 0.833 , and 0.714 between the total score of the AFCSD and the Brooke scale. Significant negative correlations existed between the total score for each functional level of the AFCSD and each functional grade of the Vignos and Brooke scales. The total scores of the CFSD varied significantly between the functional grades of the Vignos scale, and specific grades of the Brooke scale. For the AFCSD, total scores of the CFSD varied significantly between the functional levels. Conclusion We have developed a new scale and the associated classification system, to assess the functional ability of children diagnosed with DMD. Preliminary evaluation of the psychometric properties of the functional scale and classification systems indicate sufficient reliability and concurrent validity.

Keywords Duchenne muscular dystrophy, Functional scale, Ambulatory function, Scale development

Received January 3, 2018; Accepted April 9, 2018

Corresponding author: Moon Suk Bang

Department of Rehabilitation Medicine, Seoul National University College of Medicine, 101 Daehak-ro, Jongno-gu, Seoul 03080, Korea. Tel: +82-22072-2925, Fax: +82-2-743-7473, E-mail: msbang@snu.ac.kr

ORCID: Jungyoon Kim (http://orcid.org/0000-0002-6204-5170); Il-Young Jung (http://orcid.org/0000-0001-8204-8195); Sang Joon Kim (http://orcid. org/0000-0002-0479-7526); Joong-Yub Lee (http://orcid.org/0000-0003-2784-3772); Sue Kyung Park (http://orcid.org/0000-0001-5002-9707); Hyung-Ik Shin (http://orcid.org/0000-0001-8805-3104); Moon Suk Bang (http://orcid.org/0000-0002-1093-6908).

(c) This is an open-access article distributed under the terms of the Creative Commons Attribution Non-Commercial License (http://creativecommons.org/ licenses/by-nc/4.0) which permits unrestricted noncommercial use, distribution, and reproduction in any medium, provided the original work is properly cited. Copyright (C) 2018 by Korean Academy of Rehabilitation Medicine 


\section{INTRODUCTION}

Duchenne muscular dystrophy (DMD) is one of the most commonly inherited genetic muscular disorders. While no curative treatments are currently available, the use of corticosteroids and assisted ventilation delays disease progression, prolongs function, and improves the overall quality of life in patients diagnosed with DMD [1]. With advances in basic and clinical DMD research, novel treatments and interventions are being developed and evaluated, with improvement in functional status serving as the benchmark of effectiveness [2,3]. Yet, clinical scales currently available to assess the functional capacity of patients with DMD present several limitations, which restrict their use as reliable outcome measures in evaluating the effectiveness of clinical interventions and predicting the prognosis.

Principal limitations of current functional scales include non-specificity; time required to complete the assessment and poor clinical applicability and relevance; low cultural sensitivity; and poor alignment with interventions currently used for the clinical management of patients with DMD. The Vignos Functional Scale highlights the poor alignment between assessment and current intervention trends, based on an assessment of the effect of knee-ankle-foot orthosis (KAFO) on function; KAFOs are no longer commonly used due to their discomfort and the weak scientific evidence supporting their effectiveness in prolonging functional walking $[4,5]$. From a perspective of cultural sensitivity, preference for floor-sitting in Asian cultures would further, artificially, reduce the use of KAFOs [6]. Additionally, the widespread use of powered wheelchairs to promote participation is not factored in currently available functional scales [7].

Our study addresses these specific limitations of current functional scales with the development of a simplified functional scale and classification system to evaluate functional abilities in patients with DMD. Our purpose, here, is to describe the methods of development of our Comprehensive Functional Scale for DMD (CFSD) and Ambulatory Functional Classification System for DMD (AFCSD), and to report the results of preliminary testing of inter-rater reliability and concurrent validity.

\section{MATERIALS AND METHODS}

All the study procedures were approved by the Institutional Review Board of Seoul National University Hospital (No. 1110-096-382 and 1104-032-357). Informed consent, or assent as appropriate for participants' age, was obtained for the assessment of reliability and validity.

The CFSD was developed using the modified Delphi method [8]. The process consisted of three stages: item generation (stage 1); primary item reduction and scale development (stage 2); and scale evaluation (stage 3). The expert panel was composed of a single pediatric neurologist and six physiatrists. Reliability and validity testing was directed by two statisticians. Authors gathered opinions, provided feedback, and reported conclusions to the expert panel, by e-mail or mail as appropriate, throughout the developmental process and reliability and validity testing.

The AFCSD was based on the Gross Motor Function Classification System [9], the Communication Function Classification System [10], and the Manual Ability Classification System [11]. The AFCSD comprises 5 levels, defined as follows: level 1, walking at normal speed and with normal postural alignment; level 2, walking independently without an assistive device or brace, with evidence of abnormal gait patterns, such as tip-toeing or waddling, and with impaired postural alignment, such as excessive trunk lordosis; level 3, walking across only short distances, using a hand-held mobility device, such as a walker or crutch; level 4, inability to walk and use of a powered wheelchair; and level 5, need for transportation in a manual wheelchair. These 5 classification levels are presented in Fig. 1.

\section{Stage 1: Item generation}

The MEDLINE database was searched from January 1965 to June 2009 using the following combinations of terms: (Duchenne muscular dystrophy OR muscular dystrophy) AND (functional evaluation OR functional scale OR activities of daily living). The search identified 305 articles, describing the following key functional scales: the Revised Amyotrophic Lateral Sclerosis Functional Rating Scale [12]; the Barthel Index [13]; the Modified Barthel Index [14]; the Muscular Dystrophy-Specific Functional Rating Scale [15]; the Modified Hammersmith Functional Motor Scale [16]; the Motor Performance Test [17]; the 


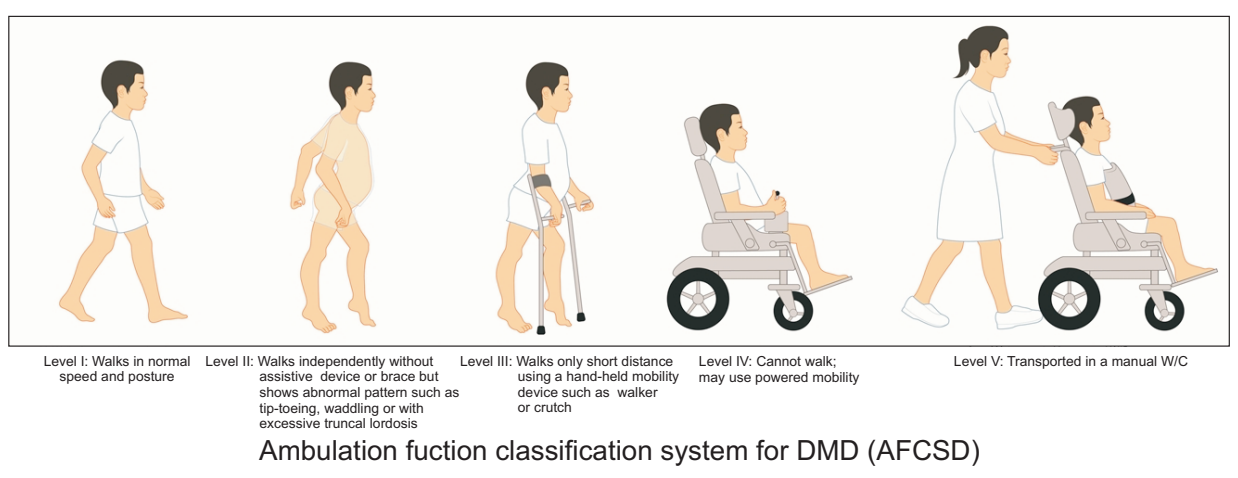

Fig. 1. Ambulatory functional classification system for Duchenne muscular dystrophy (DMD).
Pediatric Evaluation of Disability Inventory [18]; the Vignos Scale; the Brooke Scale [19]; the Wee Functional Independence Measure [20]; the Gross Motor Function Measure; the Physical Self-Maintenance Scale [21] and the measure of activities of daily living (ADL) and instrumental ADL [21]. A preliminary pool of items was generated following a series of expert panel meetings. Refinement of the preliminary item selection was conducted via a two-step process. In the first step, a closed questionnaire was sent to the members of the expert panel to obtain individual information pertaining to the importance of each item and sub-item (e.g., sitting item and related sub-items for each posture and activity, as described in Supplementary Table S1). The perceived importance of items and sub-items was measured on a Likert scale, ranging from 1 to 5 , with the following descriptions provided: very unimportant, unimportant, not important or unimportant, important, and very important. In the second step, the results of the closed-questionnaire were tabulated and summarized as a total score and a mean (SD) score for each item and sub-item, and provided to the expert panel.

Each panel member was asked to review the results and to re-score items and sub-items as they deemed applicable.

Stage 2: Primary item reduction and scale development Following the second round of scoring, ranked items were shared with the expert panel and classified into functional domains. A modified Delphi approach, in conjunction with subsequent meetings of the expert panel, was used to select relevant items and sub-items from the pool of items identified at the end of stage 1 .
Stage 3: Preliminary evaluation of the inter-rater reliability and validity of the CFSD and AFCSD

The inter-rater reliability of the CFSD and the AFCSD was evaluated in 48 boys diagnosed with DMD, with a mean age of $5.29 \pm 3.51$ years. All the items and sub-items were tested by two clinical experts on the same day, a pediatric physiatrist and a pediatric physical therapist. Items derived from established objective measurements, such as the Cobb angle of scoliosis or intelligence quotients, were not included in the evaluation of reliability.

Inter-rater reliability of the CFSD and AFCSD, as well as of the Vignos and the Brooke Scales, was evaluated using the intraclass correlation coefficient (ICC), with ICC values $>0.7$ suggesting acceptable level of reliability. BlandAltman plots and limits of agreement (mean \pm 1.96 SD) were also calculated.

The concurrent validity of the CFSD and AFCSD was evaluated against established functional scales, namely the Vignos and the Brooke Scales. Spearman correlation coefficients were calculated between the total scores of the AFCSD and both the Vignos and the Brooke scales, to provide a global measure of validity. Specific validity of the CFSD was evaluated by comparing total scores on the CFSD to scores for each grade of function on the Vignos and the Brooke scales, and for the 5 levels of the AFCSD. The level of concordance between the grades of the Vignos and Brooke scales and the levels of the AFCSD was assessed using the Kruskal-Wallis test, with the Wilcoxon rank sum test used for post-hoc analyses of differences detected between the scales, with corrections for multiple comparisons according to the false detection rate (FDR) method.

All the statistical analyses were performed using the R3.1.0 GUI, with the level of significance set at $\mathrm{p}<0.05$. 
Table 1. A comprehensive functional scale for Duchenne muscular dystrophy (CFSD)

\begin{tabular}{|c|c|c|c|c|}
\hline Domain in ICF & Item & Score & & $\begin{array}{l}\text { Item\# in } \\
\text { the scale }\end{array}$ \\
\hline \multirow[t]{26}{*}{$\begin{array}{l}\text { Body functions and } \\
\text { structures }\end{array}$} & $\begin{array}{l}\text { Severity of knee joint contrac- } \\
\text { ture }\end{array}$ & 3 & No limitation & 15 \\
\hline & & 2 & Mild limitation ( $\mathrm{ROM}>2 / 3$ in normal range) & \\
\hline & & 1 & $\begin{array}{l}\text { Moderate limitation }(1 / 3<\mathrm{ROM}<2 / 3 \text { in normal } \\
\text { range })\end{array}$ & \\
\hline & & 0 & Severe limitation $(\mathrm{ROM}<1 / 3$ in normal range) & \\
\hline & $\begin{array}{l}\text { Severity of hip joint contrac- } \\
\text { ture }\end{array}$ & 3 & No limitation & 16 \\
\hline & & 2 & Mild limitation ( $\mathrm{ROM}>2 / 3$ in normal range) & \\
\hline & & 1 & $\begin{array}{l}\text { Moderate limitation }(1 / 3<\mathrm{ROM}<2 / 3 \text { in normal } \\
\text { range })\end{array}$ & \\
\hline & & 0 & Severe limitation ( $\mathrm{ROM}<1 / 3$ in normal range) & \\
\hline & $\begin{array}{l}\text { Respiratory insufficiency } \\
\text { (ventilator assisted) }\end{array}$ & 3 & Not needed & 17 \\
\hline & & 2 & During the night time & \\
\hline & & 1 & During the night and day ( $<24$ hours) & \\
\hline & & 0 & All day long & \\
\hline & Dyspnea & 3 & None & 18 \\
\hline & & 2 & After activity & \\
\hline & & 1 & After standing (orthopnea) & \\
\hline & & 0 & In stable condition & \\
\hline & Using drug for heart disease & 3 & No & 19 \\
\hline & & 0 & Yes & \\
\hline & Scoliosis - Cobb angle [24-26] & 3 & None (Cobb's angle $<20^{\circ}$ ) & 20 \\
\hline & & 2 & Mild $\left(20<{\left.\text { Cobb's angle }<30^{\circ}\right)}^{\circ}\right.$ & \\
\hline & & 1 & Moderate (Cobb's angle $<50^{\circ}$ ) & \\
\hline & & 0 & $\begin{array}{l}\text { Severe (Cobb's angle } \geq 50^{\circ} \text { ) or post-operative } \\
\text { state }\end{array}$ & \\
\hline & $\begin{array}{l}\text { Intellectual disability (ID; } \\
\text { WISC-III or KEDI-WISC) } \\
\text { [27-29] }\end{array}$ & 3 & None & 21 \\
\hline & & 2 & Mild ID (50-69) & \\
\hline & & 1 & Moderate ID (35-49) & \\
\hline & & 0 & Severe ID $(<35)$ & \\
\hline \multirow[t]{8}{*}{ Activity } & Stair climbing & 3 & Climbs stairs without assistance & 1 \\
\hline & & 2 & Climbs stairs with aid of railing & \\
\hline & & 1 & Restrictively climbs stair with assistance & \\
\hline & & 0 & Cannot climb stairs & \\
\hline & Running & 3 & Runs with normal speed & 2 \\
\hline & & 2 & Slowly runs without assistance (other person) & \\
\hline & & 1 & Slowly runs with assistance (other person) & \\
\hline & & 0 & Cannot run & \\
\hline
\end{tabular}


Jungyoon Kim, et al.

Table 1. Continued 1

\begin{tabular}{|c|c|c|c|c|}
\hline Domain in ICF & Item & Score & & $\begin{array}{l}\text { Item\# in } \\
\text { the scale }\end{array}$ \\
\hline \multirow{4}{*}{\multicolumn{2}{|c|}{ Walking }} & 3 & Walks without assistance and rises from chair & 3 \\
\hline & & 2 & $\begin{array}{l}\text { Slowly walks unassisted but cannot rise from } \\
\text { chair }\end{array}$ & \\
\hline & & 1 & Slowly walks with assistance & \\
\hline & & 0 & Unable to walk even with assistance & \\
\hline \multirow{4}{*}{\multicolumn{2}{|c|}{ Standing }} & 3 & Stand from a floor & 5 \\
\hline & & 2 & Stand from a chair & \\
\hline & & 1 & Only stand with assistance & \\
\hline & & 0 & Cannot stand & \\
\hline \multirow{4}{*}{\multicolumn{2}{|c|}{ Sitting }} & 3 & Sit from lying without assistance & 6 \\
\hline & & 2 & Sit from lying with assistance (device or person) & \\
\hline & & 1 & Only maintain sitting position & \\
\hline & & 0 & Cannot maintain sitting position & \\
\hline \multirow{4}{*}{\multicolumn{2}{|c|}{$\begin{array}{l}\text { Transferring from bed to } \\
\text { chair }\end{array}$}} & 3 & Transfer from bed to chair without assistance & 7 \\
\hline & & 2 & Transfer with minimal assistance & \\
\hline & & 1 & Transfer with moderate assistance & \\
\hline & & 0 & Totally need assistance for transfer & \\
\hline \multirow{4}{*}{\multicolumn{2}{|c|}{$\begin{array}{l}\text { Rolling (changing body posi- } \\
\text { tion in bed) }\end{array}$}} & 3 & Fully roll in bed without assistance & 8 \\
\hline & & 2 & Roll in bed with minimal assistance & \\
\hline & & 1 & Roll in bed with moderate assistance & \\
\hline & & 0 & Cannot roll & \\
\hline \multirow{4}{*}{\multicolumn{2}{|c|}{ Eating }} & 3 & Independent & 9 \\
\hline & & 2 & With minimal assistance & \\
\hline & & 1 & With moderate assistance & \\
\hline & & 0 & Totally dependently & \\
\hline \multirow{4}{*}{\multicolumn{2}{|c|}{ Grooming }} & 3 & Independent & 10 \\
\hline & & 2 & With minimal assistance & \\
\hline & & 1 & With moderate assistance & \\
\hline & & 0 & Totally dependent & \\
\hline \multirow{4}{*}{\multicolumn{2}{|c|}{ Toileting }} & 3 & Independent & 11 \\
\hline & & 2 & With minimal assistance & \\
\hline & & 1 & With moderate assistance & \\
\hline & & 0 & Totally dependent & \\
\hline \multirow{4}{*}{\multicolumn{2}{|c|}{ Bathing }} & 3 & Independent & 12 \\
\hline & & 2 & With minimal assistance & \\
\hline & & 1 & With moderate assistance & \\
\hline & & 0 & Totally dependent & \\
\hline \multirow{4}{*}{\multicolumn{2}{|c|}{ Dressing }} & 3 & Independent & 13 \\
\hline & & 2 & With minimal assistance & \\
\hline & & 1 & With moderate assistance & \\
\hline & & 0 & Totally dependent & \\
\hline
\end{tabular}


Table 1. Continued 2

\begin{tabular}{llll}
\hline Domain in ICF & \multicolumn{1}{c}{ Item } & Score & $\begin{array}{r}\text { Item\# in } \\
\text { the scale }\end{array}$ \\
\hline Participation & $\begin{array}{c}\text { Indoor mobility (school at- } \\
\text { tendance, social interaction) }\end{array}$ & 3 & $\begin{array}{l}\text { Has active social interaction with school atten- } \\
\text { dance }\end{array}$ \\
& 2 & $\begin{array}{l}\text { Has active social interaction without school } \\
\text { attendance }\end{array}$ \\
& 1 & $\begin{array}{l}\text { Has simple social interaction without school } \\
\text { attendance }\end{array}$ \\
& 0 & Has no social interaction \\
& 3 & Using PC without assistive devices \\
& 2 & Using PC with simple assistive devices \\
\hline Using personal computer & 1 & Using PC with complex assistive devices \\
\hline Total score & 0 & Cannot use PC \\
\hline
\end{tabular}

ICF, International Classification of Functioning, Disability, and Health; ROM, range of motion; WISC-III, Wechsler Intelligence Scale Children 3rd edition; KEDI-WISC, Korean Wechsler Intelligence Scale for Children-Revised.

\section{RESULTS}

The new functional scale for Duchenne muscular dystrophy

A preliminary pool of 174 items, described in Supplementary Table S1, was identified from the structured review of the literature and the series of the expert panel meetings. These items were classified into the following 9 functional domains: mobility, ADL, muscle power, joint contracture, pulmonary function, cardiac function, scoliosis, pain, and cognitive and social function. Highly scored items in each of the 9 domains of function were extracted. In circumstances involving two or more items within a domain sharing similar component activities (e.g., transferring from the bed to a wheelchair and from the wheelchair to a toilet seat), only one item was selected. In addition, when items with a broader meaning yielded scores similar to items measuring specific attributes (e.g., the activity of eating in comparison to individual items of feeding, swallowing, and drinking, which contribute to this activity), the item with the broader meaning was included. The importance of peak cough flow, pulmonary function tests, electrocardiograms, and echocardiograms was acknowledged, and these items were excluded as they are known to be independently associated with the functional prognosis of patients with DMD.

Following the methods for item reduction, 21 items
Table 2. ICC for each item between two independent examiners

\begin{tabular}{llrrc}
\hline & \multicolumn{1}{c}{ Item } & ICC & p-value & $\mathbf{9 5 \% ~ C I ~}$ \\
\hline 1 & Stair & 0.951 & $<0.001$ & $0.912-0.972$ \\
\hline 2 & Running & 0.874 & $<0.001$ & $0.785-0.928$ \\
\hline 3 & Walking & 0.979 & $<0.001$ & $0.963-0.988$ \\
\hline 4 & Indoor & $0.680^{*}$ & $<0.001$ & $0.490-0.808$ \\
\hline 5 & Standing & 0.961 & $<0.001$ & $0.932-0.978$ \\
6 & Sitting & 0.912 & $<0.001$ & $0.846-0.950$ \\
\hline 7 & Transfer & 0.994 & $<0.001$ & $0.989-0.997$ \\
\hline 8 & Rolling & 0.872 & $<0.001$ & $0.775-0.928$ \\
\hline 9 & Eating & 0.727 & $<0.001$ & $0.560-0.837$ \\
\hline 10 & Grooming & 0.730 & $<0.001$ & $0.565-0.839$ \\
\hline 11 & Toileting & 0.829 & $<0.001$ & $0.713-0.900$ \\
\hline 12 & Bathing & 0.701 & $<0.001$ & $0.482-0.830$ \\
\hline 13 & Dressing & 0.918 & $<0.001$ & $0.851-0.955$ \\
\hline 14 & Using personal & $0.638^{*}$ & $<0.001$ & $0.434-0.780$ \\
& computers & & & \\
\hline 15 & Knee contracture & 0.909 & $<0.001$ & $0.843-0.948$ \\
\hline 16 & Hip contracture & 0.718 & $<0.001$ & $0.546-0.832$ \\
\hline 17 & Ventilator & $0.662^{*}$ & $<0.001$ & $0.469-0.795$ \\
\hline 18 & Dyspnea & $0.453^{*}$ & $<0.001$ & $0.193-0.652$ \\
\hline 19 & Drug for heart & 0.880 & $<0.001$ & $0.796-0.931$ \\
\hline AFCSD & 0.967 & $<0.001$ & $0.940-0.981$ \\
\hline
\end{tabular}

ICC, intra-class correlation coefficient; AFCSD, ambulatory functional classification for Duchenne muscular dystrophy.

${ }^{*} \mathrm{ICC}<0.700$. 
and 78 sub-items were retained across the following 7 domains: mobility (8 items), ADL (6 items), contractures (2 items), pulmonary function (2 items), cardiac function (1 item), scoliosis ( 1 item), and cognition ( 1 item) (Table 1). A variable grading system was developed to produce a range of qualitatively different levels of functional performance. For example, the item 'using drugs for heart disease' was graded on a 2-point scale, 0 and 3 representing negative and affirmative responses, respectively. The total score on the CFSD ranged from a minimum score of 0 to a maximum score of 63 , with higher scores representing higher function, and hence, less severe diseaserelated impairment. The full items and scoring systems are described in Table 1.

\section{Reliability and validity}

\section{Reliability}

The ICCs between two examiners are reported in Table 2. Two out of the 48 subjects were excluded from the analysis due to missing discrete item scores. Interrater ICC values were below the cutoff of 0.7 , set a priori, for the following four CFSD items: indoor activities (ICC $=0.680$ ), personal computer utilization ( $\mathrm{ICC}=0.638$ ), ventilator assist (ICC $=0.662$ ), and presence of dyspnea (ICC $=0.453$ ). Evaluation of the limits of agreement of the total AFCSD score between the two examiners indicated disagreement for a discrete outlier within one level (Fig. 2 ). With this exception, the overall limits of agreements ranged between -6.21 and 3.11 (Fig. 3A). These limits of agreement narrowed to a range of -5.54 to 3.19 when the items scoring ICC values $<0.7$ were removed from the calculation (Fig. 3B).

\section{Validity}

The Spearman correlation coefficient between the total score on the CFSD and on the Vignos scale was 0.833 $(p<0.001)$, and $0.714(p<0.001)$ between the total score of the CFSD and the Brooke Scale. The following significant correlations were calculated between the total CFSD score and the Vignos and Brooke scales or AFCSD: - 0.818 , -0.645 , and -0.686 for the Vignos Scale, the Brooke Scale,

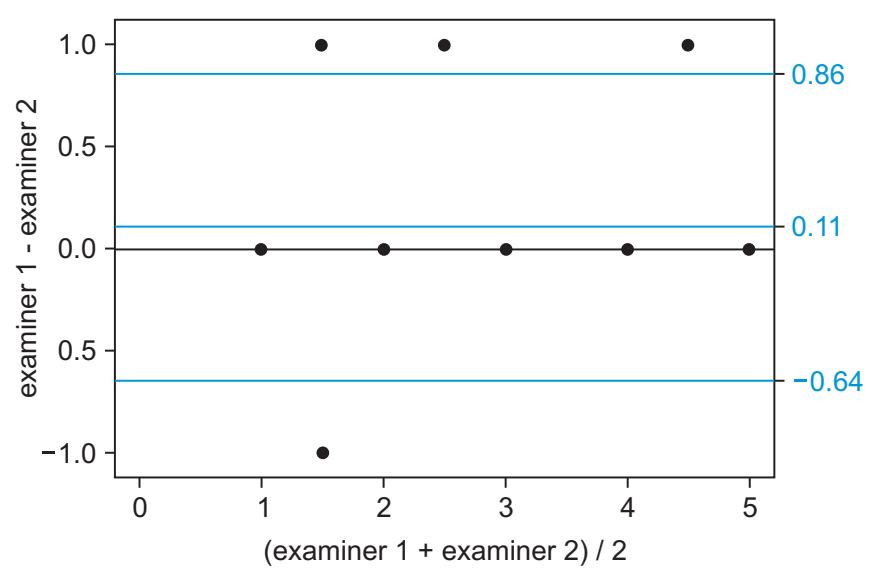

Fig. 2. Bland-Altman plot for agreements between examiners 1 and 2 in the ambulatory functional classification system for Duchenne muscular dystrophy (AFCSD). Blue horizontal lines show a $97.5 \%$ limit, median, and $2.5 \%$ limit of the agreements.
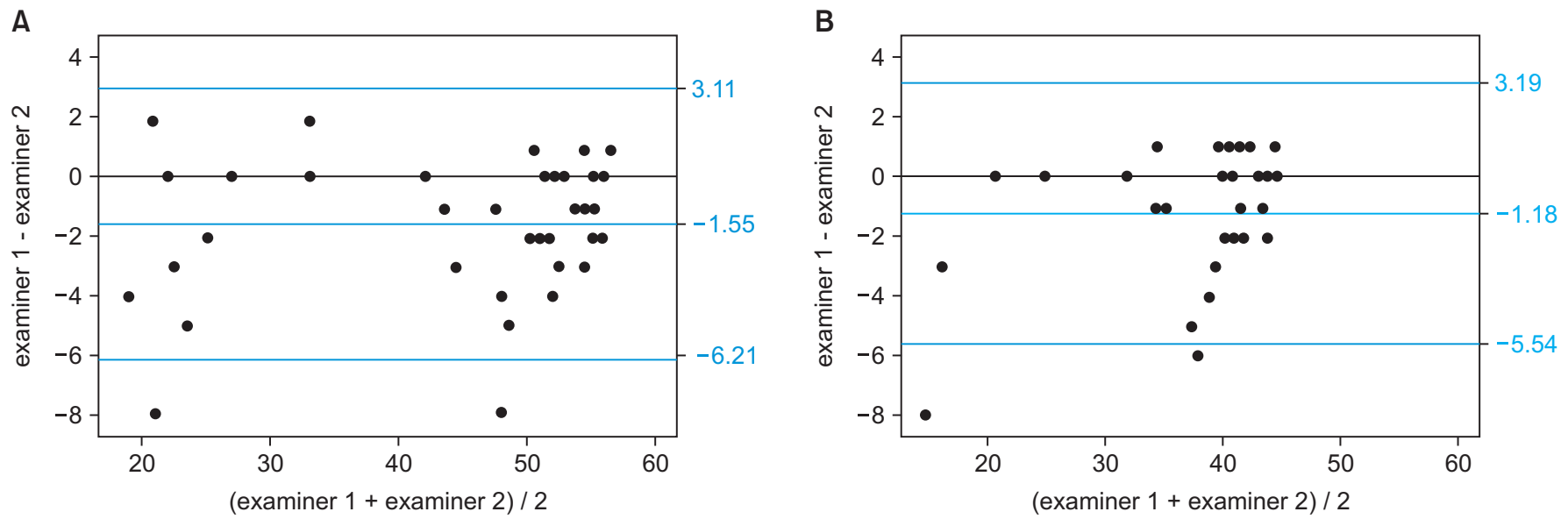

Fig. 3. Bland-Altman plot for agreements between examiners 1 and 2 in the total score of the new functional scale. (A) Total score ranging from item 1 to 19; (B) items with acceptable ( $>0.7)$ intraclass correlation coefficients. Blue horizontal lines show a $97.5 \%$ limit, median, and $2.5 \%$ limit of the agreements. 
and the AFCSD, respectively ( $\mathrm{p}<0.001$ for all pairs).

The mean (SD) scores for the CFSD score and each grade of the Vignos and Brooke scales, and the levels of the AFCSD are presented in Table 3. As shown in Fig. 4A, the total scores varied significantly between the following functional grades of the Vignos scale: 1 and 2; 1 and 4; 1 and 9; 2 and 9; 3 and 9; and 4 and 9. For the Brooke scale, the total scores were distinct for functional grades 2 and 3 (Fig. 4B). For the AFCSD, the total scores varied significantly between the functional levels 1 and 5 and 2 and 5 (Fig. 5).

\section{DISCUSSION}

In this study, we describe the development and preliminary testing of inter-rater reliability and concurrent validity of a new functional scale and functional classification system for children diagnosed with DMD, the CFSD and AFCSD, respectively. These two new clinical assessments consist of items deemed essential to the function of patients with DMD based on the results of our longitudinal study [22]. By incorporating items from all three domains of the International Classification of Functioning, Disability, and Health (ICF), including body functions and structures, activities, and participation, our novel clinical tools provide a comprehensive functional assessment of patients with DMD. Furthermore, we have improved the relevance of our assessment compared with currently available clinical tools, by including items reflective of technology utilization, such as personal computers and powered-wheelchairs. Therefore, we propose that our functional scale and classification system provide meaningful outcomes in evaluating the effectiveness of novel treatments and interventions in an effort to improve the outcomes of patients with DMD, as well as to more reliably predict clinical prognosis. The CFSD and AFCSD, therefore, represent valuable tools to include in the large number of clinical trials investigating patients with DMD.

\section{A new functional scale for Duchenne muscular dystrophy}

Novel items of the CFSD evaluating indoor activities, personal computer utilization, ventilator assistance, and presence of dyspnea scored ICC values $<0.7$. A review of these items indicates that the low reliability of the scores may reflect the vagueness of terms used, such as 'active'
Table 3. Summary of the total score in each level and grade of the AFCSD, the Vignos and the Brooke Scales

\begin{tabular}{|c|c|c|}
\hline & $\begin{array}{l}\text { Number of the } \\
\text { subjects }\end{array}$ & $\begin{array}{l}\text { Total score of new } \\
\text { functional scale }\end{array}$ \\
\hline \multicolumn{3}{|l|}{ AFCSD } \\
\hline Level 1 & 17 & $53(42-57)$ \\
\hline Level 2 & 17 & $51(33-56)$ \\
\hline Level 3 & 2 & $40.5(34-47)$ \\
\hline Level 4 & 2 & $23(17-29)$ \\
\hline Level 5 & 8 & $21.5(17-27)$ \\
\hline \multicolumn{3}{|c|}{ Vignos scale } \\
\hline 1 & 9 & $54(51-57)$ \\
\hline 2 & 19 & $51(43-55)$ \\
\hline 3 & 3 & $52(49-53)$ \\
\hline 4 & 3 & $46(42-47)$ \\
\hline 5 & 2 & $33.5(33-34)$ \\
\hline 6 & 0 & NA \\
\hline 7 & 0 & NA \\
\hline 8 & 0 & NA \\
\hline 9 & 10 & $21.5(17-29)$ \\
\hline 10 & 0 & NA \\
\hline \multicolumn{3}{|c|}{ Brooke scale } \\
\hline 1 & 33 & $51(17-57)$ \\
\hline 2 & 6 & $31.5(21-52)$ \\
\hline 3 & 4 & $25.5(21-33)$ \\
\hline 4 & 1 & $22^{\mathrm{a})}$ \\
\hline 5 & 2 & $17^{\mathrm{b})}$ \\
\hline 6 & 0 & NA \\
\hline
\end{tabular}

Values are presented as median (min-max).

AFCSD, ambulatory functional classification for Duchenne muscular dystrophy; NA, not applicable.

${ }^{a)}$ Standard deviation was not applicable because only one subject scored Brooke scale 4.

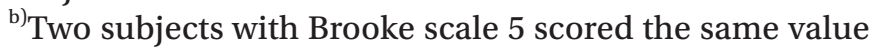
on the new functional scale.

and 'simple' social interactions, which may be interpreted differently by different examiners. Language subtleties may influence the reliability scores. As an example, while mechanical ventilators and mechanical insufflators and exsufflators have adistinct meaning in English, a common wording is used in Korean ('hoheup-bojogi' vs. 'kichimbojogi'). The low reliability scores for items on dyspnea may specifically reflect the existing vagueness surrounding the description of respiratory symptoms in children with DMD. For example, dyspnea associated with venti- 

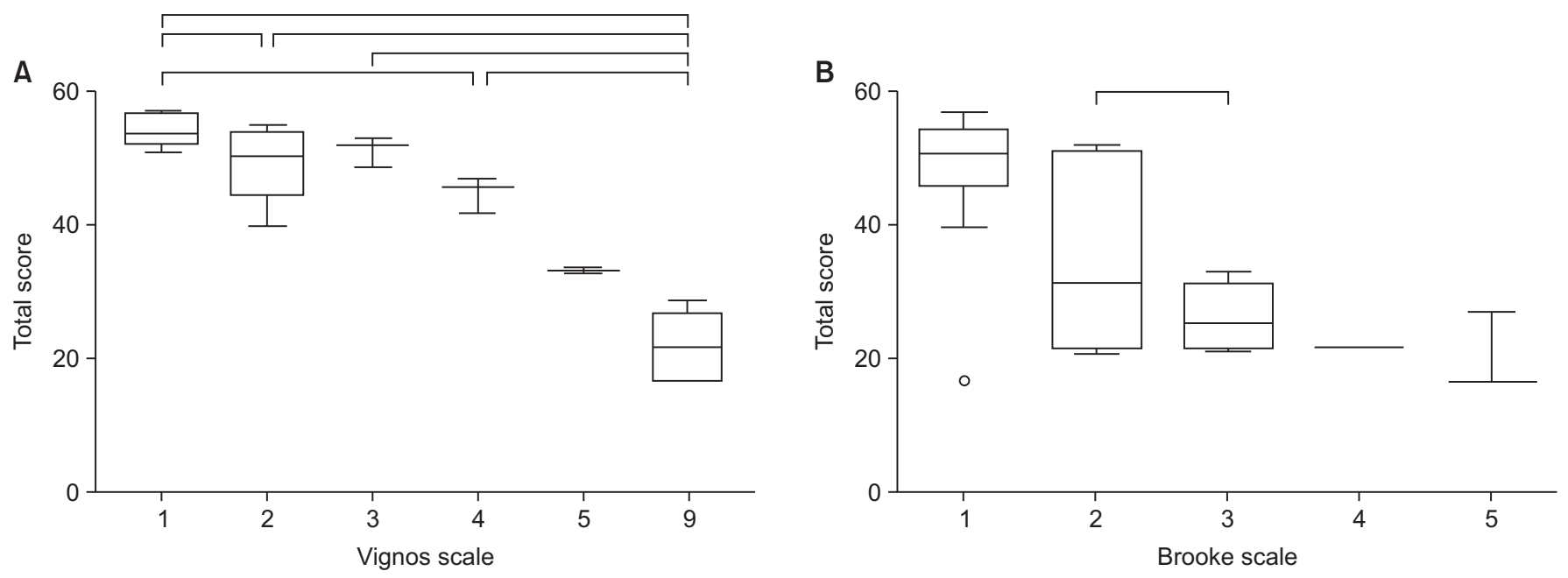

Fig. 4. Total scores of the comprehensive functional scale under each grade: (A) Vignos scale, and (B) Brooke scale. In the Vignos scale, scores varied significantly between grades 1-2, 1-4, 1-9, 2-9, 3-9, and 4-9. In the Brooke scale, scores between grade 2 and 3 differ from each other. Lower and upper margins of the box present the lower quartile (Q1) and the upper quartile $(\mathrm{Q} 3)$ of the total score. The band inside the box indicates median, and the whiskers range from Q1+1.5 interquartile range (IQR) to Q3+IQR. Hollow circles represent outliers. Horizontal lines above the box graph depict significant differences in the Wilcoxon rank sum test (adjusted $\mathrm{p}<0.05$ ).

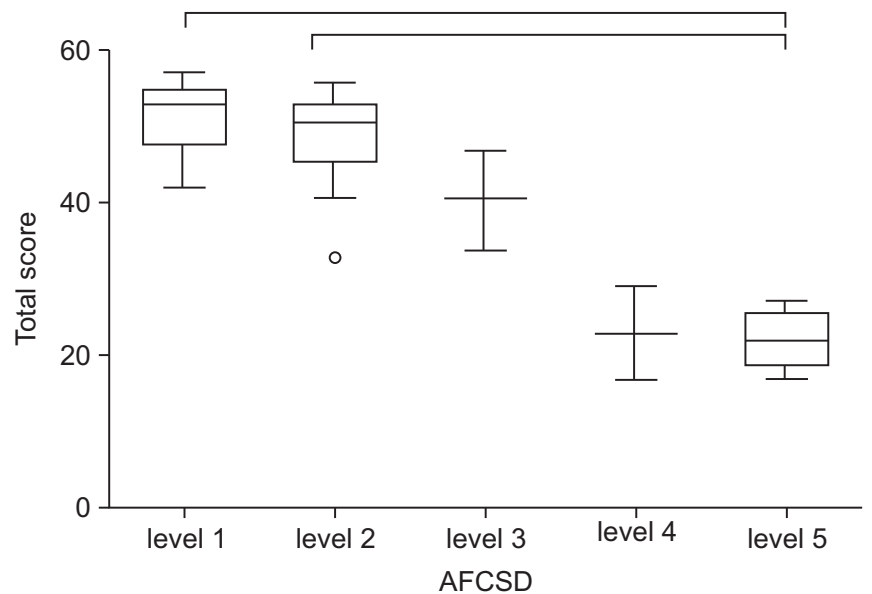

Fig. 5. Total scores in each level of the ambulatory functional classification system for Duchenne muscular dystrophy (AFCSD). Significant differences in the total score were found between 1-5, and 2-5. Lower and upper margins of the box present the lower quartile $(\mathrm{Q} 1)$ and the upper quartile (Q3) of the total score. The band inside the box indicates median, and the whiskers range from Q1+1.5 interquartile range (IQR) to Q3+IQR. Hollow circles show outliers. Horizontal lines above the box graph depict significant differences in the Wilcoxon rank sum test (adjusted $\mathrm{p}<0.05$ ).

lation insufficiency rather than oxygenation insufficiency tends to be poorly differentiated until symptoms become severe and require intervention.
The total CFSD scores correlated strongly with the total scores on the Vignos and the Brooke scales. These high correlation coefficient scores might be useful to differentiate mild functional impairments, as the scores varied significantly from those for grades 1 and 2 on the Vignos scale (Fig. 4A). This sensitivity of the CFSD and AFCSD in differentiating grades of function in children in the early (mild) phases of DMD progression might be important in measuring changes after medical interventions and rehabilitation in the early stages of DMD. However, we must also consider the benefit of less granular classification grades; as an example, grade 2 on the Brooke scale includes a broad range of total scores (Fig. 4B), which might reflect diverse compensatory strategies that children with DMD adopt to accomplish functional goals during the early stages of the disease.

\section{Ambulatory functional classification system for Duchenne muscular dystrophy}

The high Spearman correlation coefficients between the AFCSD and the Vignos and the Brooke scales indicate concurrent validity of the AFCSD. However, as 34 of the 46 participants in this study (73.9\%) were classified under level 1 or 2 on the AFCSD, with only a few children classified under levels 3 and 4 , the total CFSD scores varied significantly only between levels 1 and 5 and levels 2 and 
5. As the scores were not normally distributed, the mean (SD) values of total scores within each classification level could not be calculated.

\section{Limitations}

The study group manifested a skewed distribution of disease severity, with the majority of children in the mild phase of the disease: $28 / 46$ (60.9\%) and 33/46 (71.7\%) classified under grades 1 and 2 of the Vignos and Brooke scales, respectively, whereas $34 / 46$ (73.9\%) were classified under levels 1 and 2 of the AFCSD. Validation of the CFSD and AFCSD for children at more progressive stages of disease severity requires large-scale clinical trials, with a normal distribution of participants across all stages of DMD disease severity.

Each stage of the AFCSD represents the functional levels of children with DMD. However, it does not contain age-specific or developmental stage-specific information. Further validation and modification of each stage requires testing in a larger population of children with DMD.

The intra-rater reliability of each item of the CFSD was not tested in this study as the participants and their legal guardians refused to undergo prolonged evaluation. Intra-rater reliability of each item should be further investigated in a subsequent study. The validity of the CFSD also needs to be tested further using comprehensive evaluation tools such as the Gross Motor Functional Measure, Modified Barthel Index, Pediatric Evaluation of Disability Inventory, and Functional Independence Measure for Children (WeeFIM).

Relatively new functional scales, such as North Star Ambulatory Assessment [23] or motor function measurement scale were not included in the item generation because they were not widely used at the time this study was conducted.

\section{Conclusions}

We have developed a new scale, and associated classification system, to assess function in patients diagnosed with DMD. Preliminary evaluation of the psychometric properties of the functional scale and classification system indicate sufficient reliability and concurrent validity to include the CFSD and AFCSD in large-scale clinical trials.

\section{CONFLICT OF INTEREST}

No potential conflict of interest relevant to this article was reported.

\section{ACKNOWLEDGMENTS}

This work was funded by the grant from Seoul Broadcasting System and KG\&G Corporation. The Medical Research Collaborating Center of the Seoul National University Biomedical Research Institute provided statistical advice for sample size estimation. The authors also wish to thank Professors Seong-Eun Koh, Bum-Sun Kwon, Jeongyi Kwon, Yong Beom Shin, and Jong Hee Chae for their expertise, which has enhanced the quality of our study. We also appreciate the assistance of Juyong Kim, Yu-Sun Min, Je Ho Kim, Kwang Dong Kim, and Woo Sung Son with data collection.

\section{SUPPLEMENTARY MATERIALS}

Supplementary materials can be found via http://doi. org/10.5535/arm.2018.42.5.690. Table S1. A preliminary pool of items and mean scores for each item from the modified Delphi approach.

\section{REFERENCES}

1. Moxley RT 3rd, Pandya S, Ciafaloni E, Fox DJ, Campbell K. Change in natural history of Duchenne muscular dystrophy with long-term corticosteroid treatment: implications for management. J Child Neurol 2010;25:1116-29.

2. Voit T, Topaloglu H, Straub V, Muntoni F, Deconinck $\mathrm{N}$, Campion G, et al. Safety and efficacy of drisapersen for the treatment of Duchenne muscular dystrophy (DEMAND II): an exploratory, randomised, placebocontrolled phase 2 study. Lancet Neurol 2014;13:98796.

3. Seto JT, Bengtsson NE, Chamberlain JS. Therapy of genetic disorders-novel therapies for Duchenne muscular dystrophy. Curr Pediatr Rep 2014;2:102-12.

4. Bakker JP, de Groot IJ, Beckerman H, de Jong BA, Lankhorst GJ. The effects of knee-ankle-foot orthoses in the treatment of Duchenne muscular dystrophy: review of the literature. Clin Rehabil 2000;14:343-59. 
5. Skalsky AJ, McDonald CM. Prevention and management of limb contractures in neuromuscular diseases. Phys Med Rehabil Clin N Am 2012;23:675-87.

6. Sethi PK. The Knud Jansen lecture. Technological choices in prosthetics and orthotics for developing countries. Prosthet Orthot Int 1989;13:117-24.

7. Bushby K, Finkel R, Birnkrant DJ, Case LE, Clemens PR, Cripe L, et al. Diagnosis and management of Duchenne muscular dystrophy. Part 2. Implementation of multidisciplinary care. Lancet Neurol 2010;9:177-89.

8. Loos GP, Smith RG, Roseman C. Probable future funding priorities in maternal and child health: a modified Delphi National Survey. J Health Polit Policy Law 1985;9:683-93.

9. Palisano R, Rosenbaum P, Walter S, Russell D, Wood E, Galuppi B. Development and reliability of a system to classify gross motor function in children with cerebral palsy. Dev Med Child Neurol 1997;39:214-23.

10. Hidecker MJ, Paneth N, Rosenbaum PL, Kent RD, Lillie J, Eulenberg JB, et al. Developing and validating the Communication Function Classification System for individuals with cerebral palsy. Dev Med Child Neurol 2011;53:704-10.

11. Eliasson AC, Krumlinde-Sundholm L, Rosblad B, Beckung E, Arner M, Ohrvall AM, et al. The Manual Ability Classification System (MACS) for children with cerebral palsy: scale development and evidence of validity and reliability. Dev Med Child Neurol 2006;48:549-54.

12. Cedarbaum JM, Stambler N, Malta E, Fuller C, Hilt D, Thurmond B, et al. The ALSFRS-R: a revised ALS functional rating scale that incorporates assessments of respiratory function. BDNF ALS Study Group (Phase III). J Neurol Sci 1999;169:13-21.

13. Mahoney FI, Barthel DW. Functional evaluation: the Barthel Index. Md State Med J 1965;14:61-5.

14. Hocking C, Williams M, Broad J, Baskett J. Sensitivity of Shah, Vanclay and Cooper's modified Barthel Index. Clin Rehabil 1999;13:141-7.

15. Lue YJ, Su CY, Yang RC, Su WL, Lu YM, Lin RF, et al. Development and validation of a muscular dystrophy-specific functional rating scale. Clin Rehabil 2006;20:804-17.

16. Krosschell KJ, Maczulski JA, Crawford TO, Scott C, Swoboda KJ. A modified Hammersmith functional motor scale for use in multi-center research on spinal muscular atrophy. Neuromuscul Disord 2006;16:41726.

17. van den Beld WA, van der Sanden GA, Feuth T, Janssen AJ, Sengers RC, Verbeek AL, et al. A new motor performance test in a prospective study on children with suspected myopathy. Dev Med Child Neurol 2006;48:739-43.

18. Ostensjo S, Bjorbaekmo W, Carlberg EB, Vollestad NK. Assessment of everyday functioning in young children with disabilities: an ICF-based analysis of concepts and content of the Pediatric Evaluation of Disability Inventory (PEDI). Disabil Rehabil 2006;28:489-504.

19. Brooke MH, Griggs RC, Mendell JR, Fenichel GM, Shumate JB, Pellegrino RJ. Clinical trial in Duchenne dystrophy. I. The design of the protocol. Muscle Nerve 1981;4:186-97.

20. Ottenbacher KJ, Taylor ET, Msall ME, Braun S, Lane SJ, Granger CV, et al. The stability and equivalence reliability of the functional independence measure for children (WeeFIM). Dev Med Child Neurol 1996;38:907-16.

21. Lawton MP, Brody EM. Assessment of older people: self-maintaining and instrumental activities of daily living. Gerontologist 1969;9:179-86.

22. Jung IY, Chae JH, Park SK, Kim JH, Kim JY, Kim SJ, et al. The correlation analysis of functional factors and age with Duchenne muscular dystrophy. Ann Rehabil Med 2012;36:22-32.

23. Ricotti V, Ridout DA, Pane M, Main M, Mayhew A, Mercuri E, et al. The NorthStar Ambulatory Assessment in Duchenne muscular dystrophy: considerations for the design of clinical trials. J Neurol Neurosurg Psychiatry 2016;87:149-55.

24. Kinali M, Messina S, Mercuri E, Lehovsky J, Edge G, Manzur AY, et al. Management of scoliosis in Duchenne muscular dystrophy: a large 10-year retrospective study. Dev Med Child Neurol 2006;48:513-8.

25. Kinali M, Main M, Eliahoo J, Messina S, Knight RK, Lehovsky J, et al. Predictive factors for the development of scoliosis in Duchenne muscular dystrophy. Eur J Paediatr Neurol 2007;11:160-6.

26. Mullender M, Blom N, De Kleuver M, Fock J, Hitters $\mathrm{W}$, Horemans A, et al. A Dutch guideline for the treatment of scoliosis in neuromuscular disorders. Scoliosis 2008;3:14. 
27. Weis R. Introduction to abnormal child and adolescent psychology. 2nd ed. Los Angeles: Sage Publications; 2014.

28. AAIDD User's Guide Work Group. User's guide: to accompany the 11th edition of Intellectual disability: definition, classification, and systems of supports: applications for clinicians, educators, organizations providing supports, policymakers, family members and advocates, and health care professionals. Washington: American Association on Intellectual and Developmental Disabilities; 2012.

29. Bittles AH, Petterson BA, Sullivan SG, Hussain R, Glasson EJ, Montgomery PD. The influence of intellectual disability on life expectancy. J Gerontol A Biol Sci Med Sci 2002;57:M470-2. 


\section{SUPPLEMENTARY MATERIALS}

Table S1. A preliminary pool of items and mean scores for each item from the modified Delphi approach

\begin{tabular}{|c|c|c|}
\hline & Item & $\begin{array}{l}\text { Mean } \\
\text { score }\end{array}$ \\
\hline \multirow[t]{34}{*}{ Mobility } & Running & 4.9 \\
\hline & Can run many circuits & 3.3 \\
\hline & Can run 15 feet, stop and run back & 3.7 \\
\hline & Can jump forward 21 inches with both feet simultaneously & 3.7 \\
\hline & Stair climbing (up and down stairs) & 4.9 \\
\hline & Climbs stairs without assistance & 4.9 \\
\hline & Climbs stair with aid of railing & 4.3 \\
\hline & $\begin{array}{l}\text { Climbs stairs slowly with aid of railing (over } 25 \text { seconds for } 8 \text { standard } \\
\text { steps) }\end{array}$ & 2.7 \\
\hline & Cannot climb stairs & 5.0 \\
\hline & Walking & 5.0 \\
\hline & Walk as far as possible on their heels & 3.6 \\
\hline & Turn and walk back & 3.1 \\
\hline & Walks without assistance & 4.6 \\
\hline & Walks with aid of railing & 3.9 \\
\hline & Walks slowly with aid of railing (over 25 seconds for 8 standard steps) & 3.0 \\
\hline & Walks unassisted and rises from chair & 4.3 \\
\hline & Walks unassisted but cannot rise from chair & 4.3 \\
\hline & Walks only with assistance or long leg braces & 1.3 \\
\hline & Walks in long leg braces but requires assistance for balance & 1.1 \\
\hline & Unable to walk even with assistance & 4.3 \\
\hline & Outdoor mobility & 3.6 \\
\hline & Distance/speed outdoors & 2.1 \\
\hline & Indoor mobility (school attendance) & 3.7 \\
\hline & Distance/speed indoors & 1.7 \\
\hline & Transferring from bed to chair or wheelchair & 4.3 \\
\hline & Transferring from wheelchair to toilet & 4.4 \\
\hline & Transferring from wheelchair to bathtub or shower & 2.7 \\
\hline & Transferring from wheelchair to car & 2.9 \\
\hline & Wheelchair manipulation (manual) & 3.7 \\
\hline & Standing from a floor & 5.0 \\
\hline & Standing & 4.6 \\
\hline & Holding on with one hand & 3.7 \\
\hline & Independently & 4.3 \\
\hline & Sitting from lying through side lying & 4.3 \\
\hline
\end{tabular}


Table S1. Continued 1

\begin{tabular}{|c|c|c|}
\hline \multirow[t]{2}{*}{ Domain } & \multirow[b]{2}{*}{ Sitting } & \multirow{2}{*}{$\begin{array}{c}\begin{array}{c}\text { Mean } \\
\text { score }\end{array} \\
5.0\end{array}$} \\
\hline & & \\
\hline & Frog (floor)/chair sitting no hand support & 4.4 \\
\hline & Long sitting, no hands & 4.1 \\
\hline & Raises one hand to ear level (R/L) & 2.9 \\
\hline & Raises 2 hands to ear level & 3.3 \\
\hline & Gets to lying from sitting (safely, not accidentally) & 4.1 \\
\hline & Rolling (changing body position in bed) & 4.9 \\
\hline & Bed mobility (transfer) & 4.7 \\
\hline & Lifts head from surface in supine & 3.4 \\
\hline & 1/2; Roll from supine, both ways & 3.9 \\
\hline & Rolls prone to supine over $\mathrm{R}$ & 2.6 \\
\hline & Rolls prone to supine over $\mathrm{L}$ & 2.6 \\
\hline & Rolls supine to prone over $\mathrm{R}$ & 2.6 \\
\hline & Rolls supine to prone over $\mathrm{L}$ & 2.6 \\
\hline & Lifts head from prone (arms down by sides) & 3.6 \\
\hline & Achieves prop on forearms-head up & 3.1 \\
\hline & Achieves prop on extended arms-head up & 3.0 \\
\hline & Achieves four point kneeling & 3.3 \\
\hline & Crawls on hands and knees & 3.9 \\
\hline \multirow[t]{20}{*}{ Activities of daily living } & Eating & 5.0 \\
\hline & Drooling & 1.4 \\
\hline & Feeding & 4.7 \\
\hline & Swallowing & 4.4 \\
\hline & Drinking & 4.3 \\
\hline & Use of drinking containers & 3.6 \\
\hline & Cutting food & 2.4 \\
\hline & Grooming & 5.0 \\
\hline & Washing face and hands & 4.4 \\
\hline & Combing hair (hairbrushing) & 4.4 \\
\hline & Brushing teeth (toothbrushing) & 4.4 \\
\hline & Cutting fingernail & 3.0 \\
\hline & Cutting toenail & 2.4 \\
\hline & Shaving & 2.1 \\
\hline & Nose care & 2.0 \\
\hline & Bathing & 4.7 \\
\hline & Washing body & 4.4 \\
\hline & Toileting (getting on and off toilet) & 4.9 \\
\hline & Handling clothes & 4.1 \\
\hline & Wiping or flushing & 4.1 \\
\hline
\end{tabular}


Table S1. Continued 2

\begin{tabular}{|c|c|c|}
\hline Domain & Item & $\begin{array}{l}\text { Mean } \\
\text { score }\end{array}$ \\
\hline & Dressing & 4.9 \\
\hline & Bracing & 2.7 \\
\hline & Put on/take off formal dresses & 3.4 \\
\hline & Dressing upper part of body & 4.4 \\
\hline & Dressing lower part of body (pants) & 4.4 \\
\hline & Shoes/socks & 3.9 \\
\hline & Bladder control & 4.1 \\
\hline & Bladder incontinence & 3.7 \\
\hline & Care of perineum & 4.1 \\
\hline & Handling utensils & 2.9 \\
\hline & Bowel control & 4.3 \\
\hline & Bowel incontinence & 3.3 \\
\hline & Speech & 3.9 \\
\hline & Writing & 4.0 \\
\hline & Turning books & 3.3 \\
\hline & Card turning & 2.3 \\
\hline & Cleaning table & 2.7 \\
\hline & Pullover/front - opening garments & 2.1 \\
\hline & Fasteners & 2.3 \\
\hline & Food preparation & 2.9 \\
\hline & Washing clothes & 2.1 \\
\hline & Household chores & 2.0 \\
\hline & Managing objects over head & 3.1 \\
\hline & Picking up small, common objects & 3.6 \\
\hline & Manipulating small, common objects & 3.0 \\
\hline & Carrying large, light objects & 3.4 \\
\hline & Carrying large, heavy objects & 3.3 \\
\hline & Heavy home maintenance tasks & 2.0 \\
\hline & Bilateral lifting & 2.1 \\
\hline & Using personal computer & 4.7 \\
\hline & Using personal computer with adaptive devices & 4.3 \\
\hline \multirow[t]{9}{*}{ Muscle power } & Gower's sign & 4.6 \\
\hline & Strength of neck & 3.1 \\
\hline & Strength of trunk & 3.1 \\
\hline & Strength of knee extensor & 3.6 \\
\hline & Strength of shoulder abductor & 3.3 \\
\hline & $\begin{array}{l}\text { Starting with arms at the sides, the patient can abduct the arms in a full } \\
\text { circle until they touch above the head }\end{array}$ & 4.4 \\
\hline & $\begin{array}{l}\text { Can raise arms above head only by flexing the elbow (shortening the } \\
\text { circumference of the movement) or using accessory muscles }\end{array}$ & 4.3 \\
\hline & $\begin{array}{l}\text { Cannot raise hands above head, but can raise an } 8 \text {-oz glass of water to } \\
\text { the mouth }\end{array}$ & 4.3 \\
\hline & $\begin{array}{l}\text { Can raise hands to the mouth, but cannot raise an 8-oz glass of water to } \\
\text { the mouth }\end{array}$ & 4.1 \\
\hline
\end{tabular}


Table S1. Continued 3

\begin{tabular}{|c|c|c|}
\hline Domain & Item & $\begin{array}{l}\text { Mean } \\
\text { score }\end{array}$ \\
\hline & $\begin{array}{l}\text { Cannot raise hands to the mouth, but can use hands to hold a pen or } \\
\text { pick up pennies from the table }\end{array}$ & 4.0 \\
\hline & Cannot raise hands to the mouth and has no useful function of hands & 4.4 \\
\hline \multirow{14}{*}{$\begin{array}{l}\text { Joint contracture (range of mo- } \\
\text { tion, ROM) }\end{array}$} & Severity of neck contracture & 2.6 \\
\hline & Severity of trunk contracture & 3.1 \\
\hline & Number of contracted joints in the upper limbs & 4.0 \\
\hline & Number of contracted joints in the lower limbs & 4.1 \\
\hline & Severity of upper limb joint contractures & 4.3 \\
\hline & Finger & 3.6 \\
\hline & Wrist & 4.0 \\
\hline & Elbow & 4.1 \\
\hline & Shoulder & 4.3 \\
\hline & Severity of lower limb joint contractures & 4.4 \\
\hline & Toe & 2.6 \\
\hline & Ankle & 4.4 \\
\hline & Knee & 4.6 \\
\hline & Hip & 4.6 \\
\hline \multirow[t]{11}{*}{ Pulmonary function } & Respiratory insufficiency (ventilator assisted) & 4.7 \\
\hline & Orthopnea & 4.4 \\
\hline & Dyspnea in stable condition & 4.6 \\
\hline & Dyspnea after activity & 4.6 \\
\hline & Sputum clearance & 4.4 \\
\hline & Peak cough flow & 5.0 \\
\hline & Pulmonary function test & 4.4 \\
\hline & Forced vital capacity (FVC, L) & 4.0 \\
\hline & Maximum voluntary ventilation (L/min) & 3.9 \\
\hline & Maximal expiratory pressure $\left(\mathrm{cmH}_{2} \mathrm{O}\right)$ & 3.6 \\
\hline & Maximal inspiratory pressure $\left(\mathrm{cmH}_{2} \mathrm{O}\right)$ & 4.1 \\
\hline \multirow[t]{10}{*}{ Cardiac function } & Dyspnea after activity & 4.7 \\
\hline & Electrocardiogram (ECG) & 4.0 \\
\hline & Arrhythmia & 3.7 \\
\hline & Left ventricular dysfunction & 4.3 \\
\hline & Using drug for heart disease & 4.7 \\
\hline & Echocardiogram (EchoCG) & 4.4 \\
\hline & Fractional shortening & 3.9 \\
\hline & Ejection fraction & 4.4 \\
\hline & Dilated cardiomyopathy (DCMP); left ventricular dysfunction & 4.3 \\
\hline & Brain natriuretic peptide (BNP) & 3.7 \\
\hline \multirow[t]{3}{*}{ Scoliosis } & Scoliosis & 4.9 \\
\hline & Cobb angle (none/mild/moderate/severe) & 4.7 \\
\hline & Degree or severity & 3.7 \\
\hline
\end{tabular}


Table S1. Continued 4

\begin{tabular}{|llc|}
\hline \multicolumn{1}{|c|}{ Domain } & Item & $\begin{array}{c}\text { Mean } \\
\text { score }\end{array}$ \\
\hline Pain & Number of pain areas & 3.1 \\
\hline & Frequency of pain & 3.1 \\
\hline & Intensity of pain & 3.1 \\
\hline & Pain-inducing activities & 3.4 \\
\hline Cognition and social function & Mental retardation (KEDI-WISC, none/mild/mod/severe) & 5.0 \\
\hline & Comprehension & 3.7 \\
\hline & Comprehension of word meanings & 3.7 \\
\hline & Comprehension of sentence complexity & 4.0 \\
\hline & Expression & 3.7 \\
\hline & Functional expressive communication & 3.9 \\
\hline & Complexity expressive communication & 3.6 \\
\hline Social Interaction & 4.6 \\
\hline Social interactive play & 3.7 \\
\hline Peer interactions & 4.4 \\
\hline Community function & 4.1 \\
\hline Play with objects & 2.9 \\
\hline Problem solving & 3.3 \\
\hline Memory & 3.6 \\
\hline Time orientation & 3.3 \\
\hline Self-information & 3.0 \\
\hline Self-protection & 3.3 \\
\hline
\end{tabular}

